\title{
STAPHYLOCOCCUS AUREUS PHAGE GROUPS AND THEIR RELATION TO ANTIBIOTIC RESISTANCE PATTERN IN A TERTIARY CARE HOSPITAL, SOUTH TAMIL NADU.
}

Vazhavandal G1, Vallab Ganesh Bharadwaj B2, Uma A33, Chitra Rajalakshmi P4, Thirumalai Kolundu Subramanian $\mathrm{P}^{5}$

\section{HOW TO CITE THIS ARTICLE:}

Vazhavandal G, Vallab Ganesh Bharadwaj B, Uma A, Chitra Rajalakshmi P, Thirumalai Kolundu Subramanian P. "Staphylococcus aureus phage groups and their relation to antibiotic resistance pattern in a tertiary care hospital, south Tamil Nadu". Journal of Evolution of Medical and Dental Sciences 2013; Vol2, Issue 29, July 22; Page: 5366-5374.

ABSTRACT: OBJECTIVE: To find out the prevalent phage groups of Staphylococcus aureus strains (S. Aureus), and find out their correlation with antibiotic resistance. MATERIALS AND METHODS: A total of $104 \mathrm{~S}$. Aureus isolates were obtained from heterogenous clinical samples and their antimicrobial susceptibility was determined against 13 antibiotics by the Kirby Bauer disk diffusion method in accordance with the Clinical and Laboratory Standards Institute guidelines. They were phage typed by the international set of Staphylococcal phages at the National reference centre, Maulana Azad Medical College (MAM), New Delhi. RESULTS: Phage groups identified during this study period were III, NT, Mixed, II, and I in the order of 36, 34, 26, 5, and 3 (34.7, 32.7, 25 ,4.8, and $2.9 \%)$ respectively. Based on resistance of S. aureus strains to cefoxitin, it was observed that $78(75 \%)$ of the S. aureus were MRSA and only 26 (25\%) were MSSA. Analysis of Phage groups in relation to MRSA / MSSA revealed maximum number of MRSA 29 (37.18\%) were non-typable. All the S. aureus strains (100\%) were susceptible to vancomycin, linezolid, rifampicin, fusidic acid, clindamycin and teicoplanin. The resistance pattern of MRSA / MSSA to penicillin, oxacillin, doxycycline, erythromycin, gentamicin, co-trimoxazole, and ciprofloxacin were in the order of 98.7/ 96.2, 84.6/ 0, 21.8/11.5, 55.1/34.6, 51.3/ 7.7, 24.3/7.7, and 85.9/ 61.5\% respectively. CONCLUSION: Using the international set of bacteriophages $67.3 \%$ of $S$. aureus strains were phage typed and the predominant phage group was III -84/47. Among MRSA 37.18\% strains were non typable (NT). No strain was found in phage group $\mathrm{V}$ and non-allocated (NA). All tested isolates were sensitive to vancomycin, linezolid, rifampicin, fusidic acid, clindamycin and teicoplanin. When compared to MSSA strains, most of the MRSA strains were found to be resistant to commonly used antibiotics. Mixed group strains were significantly sensitive to gentamicin, penicillin and oxacillin $(\mathrm{P}<0.05)$. Phage group III strains were resistant to gentamicin when compared to strains of phage group I, II, Mixed.

KEY WORDS: Staphylococcus aureus; Methicillin Resistance; Bacteriophage Typing; Susceptibility testing.

INTRODUCTION: Staphylococcus aureus (S. aureus) is one of the most devastating human pathogen. It causes a broad spectrum of diseases, ranging from skin and soft tissue infection, myositis, bone and joint infection, pneumonia, endocarditis, bacteremia to life threatening infections like septicemia, toxic shock syndrome and necrotizing fasciitis ${ }^{1}$.Since the emergence of MRSA after one year of introducing methicillin, there have been several reports of MRSA infections throughout the 


\section{ORIGINAL ARTICLE}

world 1 .MRSA was once acquired almost exclusively in hospitals and long-term care facilities, but it is now spreading in the community ${ }^{2}$. MRSA has resistance not only to methicillin but also to other $\beta$ lactams and most other commonly used antibiotics, ${ }^{3}$ thus making it difficult to treat and leads to a high morbidity, mortality and socio economical burden. The increase in vancomycin resistance among MRSA and excessive use of antimicrobial agents has worsened the sensitivity.

The epidemiologic typing methods commonly used for MRSA include biotyping, antibigram, phage typing, serotyping, protein electrophoresis, zymotyping, plasmid analysis, restriction enzyme analysis, ribotyping, Pulsed field gel electrophoresis (PFGE), polymerase chain reaction mediated genomic finger printing, and Protein A gene typing 4 . Bacteriophage typing is an established method for epidemiological typing of S. aureus strains ${ }^{5}$. The phage types responsible for infections may vary from hospital to hospital, time to time, and region to region6. Various studies on epidemiology of S. aureus show that MRSA strains of certain phage types are more virulent and spread rapidly in hospitals7. Typing of these strains is important in epidemiology to differentiate and evaluate the importance of these strains in spreading the infection 7 and also essential for the establishment of national and international surveillance networks 5 . Thus the knowledge of prevalence of MRSA and their susceptibility pattern, and phage grouping becomes fundamental in the selection of appropriate empirical treatment.

This study was aimed to find out the phage groups of S. aureus, their prevalence and resistance as such study had never been conducted in this area before.

MATERIALS AND METHODS: A prospective study was designed to analyze 110 isolates of S. aureus isolates from heterogeneous clinical samples from both in and out patients of a rural tertiary teaching hospital during 2012- 2013.The study was approved by ethical clearance committee of our Institution. The sources of isolates were pus-100(90.9\%), sputum-7(6.3\%), throat swab-1(0.9\%), urine-1(0.9\%), and blood-1(0.9\%). Relevant clinical and epidemiological information were collected. Samples from which pure isolates of S. aureus obtained only were included for this study. Single morphologically distinct mannitol-positive colonies were tested for catalase, tube coagulase and slide coagulase using good laboratory practices. Cultures that were mannitol positive and coagulase - positive (Tube and slide coagulase) were considered as S. aureus. The antimicrobial susceptibility pattern was determined by the Kirby Bauer disk diffusion method in accordance with the Clinical and Laboratory Standards Institute guidelines ${ }^{8}$.The antibiotics tested include Penicillin (10U), oxacillin $(1 \mu \mathrm{g})$,cefoxitin $(30 \mu \mathrm{g})$, doxycycline $(30 \mu \mathrm{g})$, erythromycin(15 $\mu \mathrm{g})$, clindamycin $(2 \mu \mathrm{g})$, gentamicin $(10 \mu \mathrm{g})$, co-trimoxazole $(1.25+23.75 \mu \mathrm{g})$, ciprofloxacin (5 $\mu \mathrm{g})$, Linezolid(30 $\mu \mathrm{g})$, vancomycin $(30 \mu \mathrm{g})$, rifampicin $(5 \mu \mathrm{g})$, fusidic acid $(10 \mu \mathrm{g})$ and teicoplanin. S. aureus strain ATCC 25923 was used as quality control. Susceptibility to fusidic acid was interpreted according to the French standards for fusidic acid 9 .

All isolates showing an inhibition zone of $\leq 21 \mathrm{~mm}$ and $\geq 22 \mathrm{~mm}$ surrounding the Cefoxitin disk were considered as Methicillin Resistant Staphylococcus Aureus (MRSA) and Methicillin Sensitive Staphylococcus Aureus (MSSA) respectively ${ }^{8}$. All the isolates were preserved in nutrient agar butt. For bacteriophage typing, these isolates were sent to the National reference centre, Maulana Azad Medical College, New Delhi for Staphylococcal phage typing, and results for 104 were obtained. Six strains were contaminated. The typing was done employing 23 sets of phages, in a routine test dilution (RTD) X 100. The strains were classified as GroupI- 29, 52, 52A, 79,80, Group II - 


\section{ORIGINAL ARTICLE}

3A, 3C, 55, 71, Group III -6, 42E ,47 ,53 ,54, 75, 77, 83A, 84, 85, Group V-94, 96 and non-allocated 81, 95.

Statistical analysis was carried out using SPSS package. Chi square test was used to compare the antibiotic susceptibility between MSSA and MRSA strains, and between phage groups.

RESULTS: A total of 110 isolates of S.aureus strains were obtained from different clinical samples of the hospital. Pus accounted for the majority of isolates that is 100(90.9\%). Six were contaminated. Phage groups identified during this study period were III, NT, Mixed, II, and I in the order of 36, 34, 26,5 , and 3 (34.7, 32.7, $25,4.8$, and $2.9 \%$ ) respectively. Based on resistance of S. aureus strains to cefoxitin, it was observed that 78 (75\%) of the S. aureus were MRSA and only 26 (25\%) were MSSA.

Distribution of MRSA and MSSA according to phage groups is shown in Fig-1. No MSSA and only 3\% of MRSA belonged to phage group I; 3.84\% of MSSA and 5.13\% of MRSA to phage group II; $42.31 \%$ of MSSA and $32.1 \%$ of MRSA to phage group III respectively. No S. aureus strains belonged to phage group V and NA, $19.23 \%$ of MSSA and $21.79 \%$ of MRSA to mixed phage group; $37.2 \%$ of MRSA and 8.3\% of MSSA were non typable. As it is shown in Table-1, the Mixed phage group strains were statistically significantly susceptible to gentamicin $(\mathrm{p}<0.05)$, oxacillin $(\mathrm{p}<0.05)$ \& penicillin. The strains of phage group III were more resistant to gentamicin.

The antibiotic susceptibility patterns of the isolates in relation to methicillin sensitivity are presented in Tables-2. All the S. aureus strains were susceptible to vancomycin, linezolid, teicoplanin, rifampicin, fusidic acid and clindamycin The resistance pattern of MRSA / MSSA to penicillin, oxacillin, doxycycline, erythromycin, gentamycin, co-trimoxazole, and ciprofloxacin were in the order of $98.7 / 96.2,84.6 / 0,21.8 / 11.5,55.1 / 34.6,51.3 / 7.7,24.3 / 7.7$, and $85.9 / 61.5 \%$ respectively.

Comparing the susceptibility of MSSA \& MRSA isolates to antibiotics (Table-2) it was determined that MSSA strains were statistically significantly more susceptible to oxacillin $(\mathrm{p}<0.001)$ gentamicin $(\mathrm{p}<0.001)$, and ciprofloxacin $(\mathrm{p}<0.01)$.

DISCUSSION: Staphylococcus aureus continues to be a dangerous pathogen for both community acquired as well as hospital acquired infections. MRSA strains are prevalent worldwide which were considered initially as nosocomial pathogens but now are emerging in the community. Infections caused by this multi-drug resistant MRSA are matter great concern. The bacteriophage typing is used as a precise identification method of $\mathrm{S}$. aureus and has provided valuable information in epidemiological studies of infection in the community5.In resource limited countries like India, still phage typing remains the major tool for epidemiological analysis. Though phage typing is done at free of cost in National reference centre, MAM College,New Delhi, most of the medical colleges are not utilizing the services. So epidemiological data are lacking. No study from South India have been reported to compare our study results. Efforts must be made to compare molecular epidemiology also. 
Table-1: Comparitive analysis of Staphylococcal phage groups of present study with other reported previous studies

\begin{tabular}{|c|c|c|c|c|c|c|}
\hline $\begin{array}{c}\text { Phage } \\
\text { group }\end{array}$ & $\begin{array}{c}\text { Presentstudy, } \\
\text { 2013(\%), } \\
\text { MSSA/MRSA }\end{array}$ & $\begin{array}{c}\text { Faridkot,India, } \\
198921(\%)\end{array}$ & $\begin{array}{c}\text { Nagpur,200012 } \\
(\%) \text { (MRSA) }\end{array}$ & $\begin{array}{c}\text { Maharastra } \\
2012^{13}\end{array}$ & $\begin{array}{c}\text { ND,20087 (\%) } \\
\text { (MSSA/MRSA) }\end{array}$ & $\begin{array}{c}\text { Lithunia,20006 } \\
\text { (MSSA/MRSA) }\end{array}$ \\
\hline I & $0 / 3.84$ & 20.83 & 0 & 13.55 & $32 / 9.45$ & $10.1 / 6.3$ \\
\hline II & $3.84 / 5.13$ & 1.7 & 0 & 11.8 & $10.11 / 2.7$ & $26.6 / 6.3$ \\
\hline III & $42.3 / 32.1$ & 12.5 & 9 & 10.15 & $8.99 / 14.9$ & $12.9 / 31.2$ \\
\hline NA & $0 / 0$ & 0 & 0 & 0 & $20.22 / 2.7$ & $5.8 / 0$ \\
\hline MIX & $19.2 / 21.7$ & 1.1 & 25 & 17 & $10.1 / 10.8$ & $12.9 / 0$ \\
\hline NT & $8.9 / 37.2$ & 31.39 & 63.6 & 44.25 & 29.37 & $20.9 / 56.2$ \\
\hline V & $0 / 0$ & 0 & 0 & 0 & $2.24 / 0$ & $10.8 / 0$ \\
\hline
\end{tabular}

In our study, Phage group III-84/47 was predominant amongst MRSA and MSSA strains. In accordance with our study predominance of phage group III in MRSA strains has been reported by a study from Maulana Azad medical college, New Delhi ${ }^{7}$ and Lithuania ${ }^{6}$. On the contrary to our study, Kareiviene et $a^{6}$ reported higher incidence of phage group II- 3C among MSSA. Zierdt et al ${ }^{10}$ observed a higher percentage (54\%) of Mixed group when compared to 25\% in our study. However Bhat et al ${ }^{11}$ reported almost equal distribution of the typable strains in phage groups I, II and III.

Non-typability of S.aureus strains is a major problem employing the available sets of phages in India and other developing countries.In our study $37.2 \%$ were non-typable. On the contrary, studies from Nagpur ${ }^{12}$ and Lithuania ${ }^{6}$ reported higher incidence of non typable MRSA. This non typability can be reduced by using RTD x 100 ,incubation at $48{ }^{\circ} \mathrm{c}$ prior to test and the development of new phages 4 .

In our study, the prevalence of MRSA was found to be $75 \%$.It was found to be $2 \%$ in Netherlands and Switzerland, to 70\% in Japan and Hong Kong $(13,14), 48.3 \%$ in Yemen ${ }^{15}$, and 5.8\% ${ }^{6}$ in Lithuania. When compared with our results, lower prevalence rates of MRSA were recorded by Khadri et al- $48.3 \%{ }^{16}$, Saikia et al $-34.78 \%{ }^{17}$, Mehndiratta et al $-29.36 \%{ }^{7}$,Pai et a ${ }^{18}-29.1 \%$.

In our study, the resistance to different antibiotics among MRSA strains was higher than those MSSA and this phenomenon was reported elsewhere ${ }^{19}, 20$. Because of the resistance to all commonly used anti staphylococcal antibiotics, it is necessary to test newer group of antibiotics such as vancomycin and linezolid routinely. In our study all the S. aureus strains were susceptible to vancomycin and linezolid which is in accordance with Joshi et al ${ }^{20}$.Our study showed $100 \%$ sensitivity to rifampicin, clindamycin and fusidic acid which is in contrary to Mehndiratta et al7 ${ }^{7}$ In our survey 96.2 \%MSSA strains were resistant to penicillin. Pai et al ${ }^{18}$ reported $100 \%$ resistance to penicillin among MSSA strains. All the MSSA in our study were sensitive to oxacillin. As vancomycin 


\section{ORIGINAL ARTICLE}

is considered inferior to $\beta$-lactams for the treatment of MSSA infections, reduced use of vancomycin to $\beta$-lactams should be encouraged in all cases of MSSA ${ }^{20}$. Preservation of glycopeptides and linezolid for use only in MRSA cases should be encouraged. Resistance to ciprofloxacin among MRSA strains in our study correlated well with a study from Assam (87.5\%) 17. Previous study from Assam showed only $22.8 \%$ resistance to ciprofloxacin ${ }^{14}$. The rapid emergence of resistance to ciprofloxacin is probably due to the indiscriminate and empirical use of these drugs and lack of proper antibiotic policy in clinical practice.

Antimicrobial susceptibility pattern further revealed that doxycycline and co-trimoxazole still can be the most effective drug against MRSA strains. A study from Maharashtra observed gentamicin (91.5\%), erythromycin as the most effective drug ${ }^{13}$. We reported significant resistance to gentamicin among phage group III strains and sensitivity to penicillin, oxacillin \& gentamicin among mixed phage groups. On the contrary Sanjay et al ${ }^{13}$ reported greater frequency of penicillin resistance among mixed phage group. However Arora et al ${ }^{21}$ reported there was no co-relation between the phage type and antibiotic sensitivity pattern. Phage types and antibiotic resistance reports are contradicting each other. Contradiction may be related to 1) time of study, 2) geographical area, 3) antibiotic availability \& use, 4) prescription pattern, 5) population movement.

Larger studies need to be done in various geographical regions of the country to better define the epidemiology, mechanism of multi drug resistance (MDR) in S. aureus and its clinical implications ${ }^{22}$. Hence accurate typing is essential for the epidemiological monitoring of MRSA isolates and implementing the infection control measures to control the transmission of these infections.

Results in our study indicated a high level of resistance to widely used antibiotics among MRSA. An appropriate knowledge on the current sensitivity pattern of MRSA is very essential for appropriate treatment options.

CONCLUSION: Phage group prevalent in this study is different from other parts of India. Since sparse articles on Staphylococcus aureus phage grouping from South India have been reported we could not compare our study results with other. All the medical colleges should be motivated to send the isolates for phage typing to strengthen the epidemiological data. This has to be done consistently to analyze changing trends in the spread. Doxycycline, cotrimoxazole, gentamicin and erythromycin are the drugs of choice in that order. These antibiotics can be recommended for treatment of Staphylococcal infections where immediate report is not available or antibiotic testing is not possible. According to this study all the MRSA strains are susceptible to vancomycin, linezolid and teicoplanin which should be used discriminately to avoid the emergence of superbug. However increasing incidence of Vancomycin resistant Staphylococcus aureus (VRSA) 22 indicates regular monitoring of vancomycin sensitivity and regular testing should be carried out further. A regular surveillance of hospital associated infection including monitoring antibiotic sensitivity pattern of MRSA and implementing strict drug policy are essential to control the spread of multi drug resistance.

The limitation of our study is that it is a single centre study and comparability within Southern India could not be done because of the non availability of data from this area. Strength of the study is that almost all the isolates were confirmed by National reference centre for 
Staphylococcal phage typing ,MAM college, New Delhi and likely to be the earliest study from the Southern India providing epidemiology of Staphylococcal phage typing.

ACKNOWLEDGEMENT: Authors would like to thank the technicians and staff in the study hospital at Irungalur, Trichy for excellent co-operation and technical assistance and thanks to Miss. S.K. Saranya for helping in the preparation of manuscript.

Table 2: Susceptibility of Methicillin Sensitive Staphylococcus aureus and Methicillin Resistant Staphylococcus aureus to antibiotics

\begin{tabular}{|c|c|c|c|c|}
\hline \multirow{2}{*}{$\begin{array}{c}\text { Antibiotics n(\%) } \\
\text { total sensitive }\end{array}$} & \multicolumn{2}{|c|}{ MSSA(n=26) } & \multicolumn{2}{|c|}{ MRSA(n=78) } \\
\hline & Sensitive & Resistant & Sensitive & Resistant \\
\hline Penicillin 2(1.92) & $1(3.8 \%)$ & $\begin{array}{c}25 \\
(96.2 \%) \\
\end{array}$ & $1(1.3 \%)$ & $77(98.7 \%)$ \\
\hline Oxacillin 38(36.5) & $26(100 \%)^{*}$ & $\mathbf{0}$ & $12(15.4 \%)$ & $66(84.6 \%)$ \\
\hline Doxycycline 84(80.8) & $23(88.5 \%)$ & $3(11.5 \%)$ & $61(78.2 \%)$ & $17(21.8 \%)$ \\
\hline Erythromycin 52(50) & $17(65.4 \%)$ & $9(34.6 \%)$ & $35(44.9 \%)$ & $43(55.1 \%)$ \\
\hline $\begin{array}{l}\text { Clindamycin } \\
\text { 104(100) }\end{array}$ & $26(100 \%)$ & $\mathbf{0}$ & $78(100 \%)$ & $\mathbf{0}$ \\
\hline Gentamycin 62(59.6) & $\begin{array}{c}24 \\
(92.3 \%)^{*}\end{array}$ & $2(7.7 \%)$ & $38(48.7 \%)$ & $40(51.3 \%)$ \\
\hline $\begin{array}{l}\text { Cotrimoxazole } \\
83(79.8)\end{array}$ & $24(92.3 \%)$ & $2(7.7 \%)$ & $59(75.7 \%)$ & $19(24.3 \%)$ \\
\hline $\begin{array}{l}\text { Ciprofloxacin } \\
21(20.2)\end{array}$ & $\begin{array}{c}10 \\
(38.5 \%)^{* *}\end{array}$ & $\begin{array}{c}16 \\
(61.5 \%)\end{array}$ & $11(14.1 \%)$ & $67(85.9 \%)$ \\
\hline Linezolid 104(100) & $26(100 \%)$ & $\mathbf{0}$ & $78(100 \%)$ & $\mathbf{0}$ \\
\hline $\begin{array}{l}\text { Vancomycin } \\
104(100)\end{array}$ & $26(100 \%)$ & $\mathbf{0}$ & $78(100 \%)$ & $\mathbf{0}$ \\
\hline Rifampicin 104(100) & $26(100 \%)$ & $\mathbf{0}$ & $78(100 \%)$ & $\mathbf{0}$ \\
\hline $\begin{array}{ll}\text { Fusidic } & \text { acid } \\
104(100) & \end{array}$ & $26(100 \%)$ & $\mathbf{0}$ & $78(100 \%)$ & $\mathbf{0}$ \\
\hline $\begin{array}{l}\text { Teicoplanin } \\
\text { 104(100) }\end{array}$ & $26(100 \%)$ & $\mathbf{0}$ & $78(100 \%)$ & $\mathbf{0}$ \\
\hline
\end{tabular}




\section{ORIGINAL ARTICLE}

Table 3: Susceptibility of S. aureus phage groups to antimicrobial agents

\begin{tabular}{|c|c|c|c|c|c|c|c|c|c|}
\hline \multirow{2}{*}{$\begin{array}{c}\text { Phage } \\
\text { group }\end{array}$} & \multirow{2}{*}{$\begin{array}{c}\mathrm{N}(\%) \\
(\mathrm{n}=104)\end{array}$} & \multicolumn{9}{|c|}{ Antimicrobial agents -n (\%) } \\
\cline { 3 - 11 } & $\mathrm{P}$ & OX & CEFOX & D & ERY & GEN & COT & CIP \\
\hline I & $3(2.9)$ & 0 & 0 & 0 & $3(100)$ & $1(33.3)$ & $3(100)$ & $3(100)$ & $1(33.3)$ \\
\hline II & $5(4.8)$ & 0 & $2(40)$ & $1(20)$ & $4(80)$ & $2(40)$ & $4(80)$ & $4(80)$ & $2(40)$ \\
\hline III & $36(34.7)$ & 0 & $13(36.1)$ & $11(31)$ & $31(86.1)$ & $19(52.8)$ & $16(44.5)^{* *}$ & $28(77.8)$ & $7(19.4)$ \\
\hline NT & $34(32.7)$ & 0 & $9(26.5)$ & $5(14.7)$ & $24(70.6)$ & $18(52.94)$ & $18(52.94)$ & $27(79.4)$ & $6(17.64)$ \\
\hline Mixed & $26(25)$ & $2(7.7 \%)^{* *}$ & $14\left(53.84^{* *}\right)$ & $9(3.46)$ & $22(84.6)$ & $12(46.15)$ & $\begin{array}{c}21(80.77)^{*} \\
*\end{array}$ & $21(80.76)$ & $5(19.23)$ \\
\hline
\end{tabular}

$\left({ }^{* *} \mathrm{p}<0.05\right)$

Figure1: Distribution of MSSA and MRSA according to Phage groups

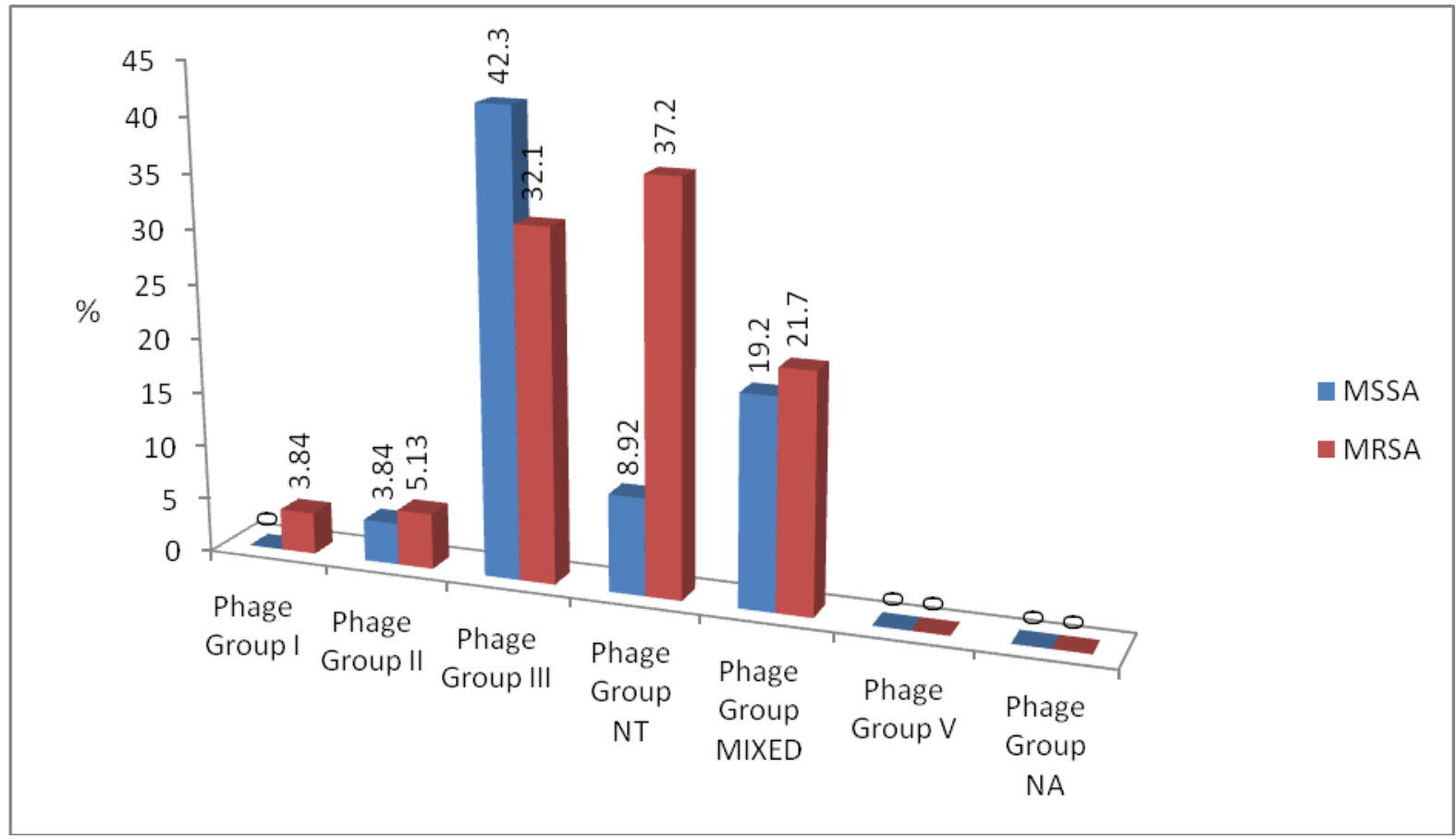

Phage Group Mixed includes I,III; III,NA; I,III,NA; I,III,V.

\section{REFERENCES:}

1. Lowy FD. Staphylococcus aureus infections. N Engl J Med 1998; 339: 520-532.

2. Chambers HF. The changing Epidemiology of Staphylococcus aureus? Emerg Infect Dis 2001;7:178-85

3. Brumfitt W, Hamilton-Miller J. Methicillin -resistant Staphylococcus aureus. N Engl J Med 1989; 9: 1188-96

4. Weller T M A, Methicillin- resistant Staphylococcus aureus typing methods: which should be the international standard? Journal of Hospital Infection 2000;44:160-172

5. Mehndiratta PL, Bhalla P .Typing of Methicillin resistant Staphylococcus aureus: A technical review. Indian J Med Microbiol 2012; 30:16-23 


\section{ORIGINAL ARTICLE}

6. Kareiviene V, Pavilonis A, Sinkute G, Liegiute S, Gailiene G. Staphylococcus aureus resistance to antibiotics and spread of phage types. Medicina (Kaunas) 2006; 42(4)

7. Mehndiratta PL, Gur R, Saini S, Bhalla P. Staphylococcal aureus phage types and their correlation to antibiotic resistance. Indian J Pathol Microbiol 2010; 53:738-41

8. Clinical and Laboratory Standars Institute, "Performance standard for antimicrobial susceptibility testing," 17th informational supplement, document M100-S17, Wayne, Pa, USA, 2007.

9. Soussy C J, Carret G, Cavallo J D, et al , "Antibiogram commitee of the French society of microbiology society. Report 2000-2001," Pathologie Biologie, 2000; 48(9): 832-871.

10. Zierdt CH, Robertson EA, William RL, Mac Lowry DJ. Computer analysis of Staphylococcus aureus phage typing data from 1957 to 1975, citing epidemiological trends and natural evolution within phage typing system. Appl Environ Microbiol 1980; 39: 623-9.

11. Bhat SD, Deshmukh AB, Damle AS. Bacteriophage typing and antibiotic sensitivity pattern of Staphylococcus aureus from clinical samples. Ind J Med Microbiol 1991; 9:173-178.

12. Tahnkiwale SS, Roy S, Jalgaonkar S V. Methicillin resistance among isolates of Staphylococcus aureus : Antibiotic sensitivity pattern \& phage typing. Indian J Med Sci [serial online] 2002; 56:330-4.

13. Sanjay M W, Sarita N K, Mangala PG. Multi drug resistance and Phage pattern of Staphylococcus aureus in Pyoderma case. JKIMSU,(2012), 1(1) 48-54

14. Majumder D, Bordoloi JN, Phukan AC, Mahanta J. Antimicrobial susceptibility pattern among methicillin resistant staphylococcus isolates in Assam. Indian J Med Microbiol 2001;19:13840

15. Abdul Rahman H. Al-Baidani, Wagiah A. El-Shouny and Taha M.Shawa. Antibiotic susceptibility pattern of Methicillin -Resistant Staphylococcus aureus in Three Hospitals at Hodeidah city, Yemen. Global J. Pharmacol.2011; 5 (2):10-111,

16. Khadri $\mathrm{H}$ and Alzohairy $\mathrm{M}$, Prevalence and antibiotic susceptibility pattern of methicillin resistant and coagulase-negative staphylococci in a tertiary care hospital in India. International J. Medicine and Medical Sci.2010;2(4):116-120

17. Saikia L, Nath R, Choudhury B, Sarkar M. Prevalence and antimicrobial susceptibility pattern of methicillin- resistant Staphylococcal aureus in Assam. Indian J Crit Care Med JulySeptember 2009; 13(3)156-158.

18. Pai V, Rao VI, Rao SP. Prevalence and Antimicrobial susceptibility pattern of Methicillinresistant Staphylococcus aureus (MRSA) isolates at tertiary Care Hospital in Mangalore, South India.

19. Verma S, Joshi S, Chitnis V, Hemwani M and Chitnis D. Growing problem of methicillin resistant Staphylococci, Indian Scenario. Indian J Med Sci. 2000;54:535-540

20. Joshi S, Ray P, Manchanda V, Bajaj J et al. Methicillin resistant Pattern in India: Prevalence \& susceptibility pattern. Indian J Med Res 2013;137:363-369

21. Arora U, Jesupadam T, Jain PK Predominant phage types of coagulase positive staphylococci in hospital infections. Indian J Med Sci 1999;53:10-3

22. Thati V, Channappa T. Shivannavar \& Subhaschandra M. Gaddad. Vancomycin resistance among methicillin resistant Staphylococcus aureus isolates from intensive care units of tertiary care hospitals in Hyderabad .Indian J Med Res 2011; 134: 704-708 


\section{ORIGINAL ARTICLE}

\section{AUTHORS:}

1. Vazhavandal G.

2. Vallab Ganesh Bharadwaj B.

3. Uma A.

4. Chitra Rajalakshmi P.

5. Thirumalai Kolundu Subramanian P.

\section{PARTICULARS OF CONTRIBUTORS:}

1. Assistant Professor, Department of Microbiology, Chennai Medical College Hospital and Research Centre, (SRM Group), Irungalur, Tiruchirapalli, Tamilnadu, India

2. Assistant Professor, Department of Microbiology, Chennai Medical College Hospital and Research Centre, (SRM Group), Irungalur, Tiruchirapalli, Tamilnadu, India

3. Professor and Head, Department of Microbiology, Chennai Medical College Hospital and Research Centre, (SRM Group), Irungalur, Tiruchirapalli, Tamilnadu, India
4. Professor, Department of Microbiology, Chennai Medical College Hospital and Research Centre, (SRM Group), Irungalur, Tiruchirapalli, Tamilnadu, India

5. Professor and Head, Department of Medicine, Chennai Medical College Hospital and Research Centre, (SRM Group), Irungalur, Tiruchirapalli, Tamilnadu, India

\section{NAME ADRRESS EMAIL ID OF THE CORRESPONDING AUTHOR:}

Dr. G. Vazhavandal, Dept. of Microbiology, D 4 Staff Quarters, Chennai Medical College Hospital and Research Centre,

(SRM Group), Irungalur, Tiruchirapalli,

Tamilnadu, India 621105

Email- hemarathinam2006@gmail.com

Date of Submission: 15/07/2013.

Date of Peer Review: 15/07/2013.

Date of Acceptance: 16/07/2013.

Date of Publishing: 18/07/2013 